\title{
A Seven-Dimensional Building Information Model for the Improvement of Construction Efficiency
}

\author{
Zhimin Wang $\mathbb{D I}^{1}$ and Jin Liu $\mathbb{1}^{2,3}$ \\ ${ }^{1}$ School of Accounting, Guangdong University of Foreign Studies, Guangzhou 510006, China \\ ${ }^{2}$ College of Civil Engineering and Architecture, Wenzhou University, Wenzhou 325025, China \\ ${ }^{3}$ Shanghai LubanSoft Company, Shanghai 200092, China
}

Correspondence should be addressed to Jin Liu; liujin0577@qq.com

Received 1 June 2020; Revised 17 November 2020; Accepted 7 December 2020; Published 21 December 2020

Academic Editor: Roberto Nascimbene

Copyright (C) 2020 Zhimin Wang and Jin Liu. This is an open access article distributed under the Creative Commons Attribution License, which permits unrestricted use, distribution, and reproduction in any medium, provided the original work is properly cited.

\begin{abstract}
With the fast expansion of major cities in China, increasing scale, complex, and tall buildings have been built to meet the increasing commercial and living demand. However, the efficiency of project management and investment is not always satisfactory. To solve this problem, a seven-dimensional building information model (7D BIM) is developed. To do this, a 3D BIM is firstly developed, which consists of architecture model, equipment model, steel framework model, other solid models, etc. Then, a 1D schedule management model and a 3D project management model (bidding management, enterprise quota management, and process management) have been integrated into the 3D BIM, thus forming a 7D BIM for a complex project. By providing a clear $3 \mathrm{D}$ vision in modeling the construction process, the proposed 7D model can be applied to help engineers/project managers carry out clash detection, structure design, modification, equipment installation, 3D project management, and maintenance after construction. The performance of this model has been demonstrated through a case study of a complex project launched in China. The study shows that the implementation of the 7D BIM has achieved significant cost and time saving as well as project quality and work efficiency improvement.
\end{abstract}

\section{Introduction}

With the fast expansion of major cities in China, more and more large-scale, complex, and tall buildings have been built to meet the increasing commercial and living demand [1]. Challenges of these complex projects include poor geology conditions [1, 2], environmental impact and regulations [3], poor process management, budget constraints, safety assessment, and future maintenance [4]. Stakeholders from different sectors are involved in the whole process of construction, including owners, project designers, construction companies, management teams, quality and safety regulation authorities, and contractors. The complexity of project construction and cooperation among stakeholders make the efficiency of project management less satisfaction in most cases [5].

As known, BIM has been proposed to provide an effective platform for enhancing the collaboration among construction sectors, management teams, and owners, through integrating related data and information for project participants $[6,7]$. The close cooperation may help improve the quality of design/construction [8], reduce repetition or rework [9], and promote efficiency and quality in construction and management $[10,11]$, thus leading to cost reduction and time savings $[12,13]$. BIM also enables a life cycle management of construction, including processes of primary project assessment, scheduling, design, construction (equipment installation, budget control, process management), operation management, maintenance, modification, and demolition $[14,15]$. Thus, BIM plays an important role in achieving project success. Surveys show that BIM has been widely adopted in construction projects in US [16], France and German [10], and the UK [17]. BIM is in the initial stage of development in China, facing the problems of low level of BIM software awareness [18] and 
non-user-friendly format [6]. Considering the challenges involved in traditional construction, Chinese government introduced regulation articles to adopt BIM as a new technological advancement in construction management in 2015, thus encouraging construction sectors to achieve success through a sustainable and high-efficient way [19]. Nevertheless, the academic research and practical experiences of higher-level BIM development and implementation in China were inadequate.

Based on the BIM technology, this study proposed a 7D BIM to solve the difficulties and achieve success in complex projects. The 7D BIM is built by integrating a traditional 3D BIM with a $1 \mathrm{D}$ schedule management model and a $3 \mathrm{D}$ project management model. The 7D BIM can be applied to help engineers/project managers carry out clash detection, structure design modification, equipment installation, 3D project management, schedule management, and maintenance after construction. The proposed 7D BIM provides a new perspective of BIM development by integrating a bunch of $3 \mathrm{D}$ project management models rather than a stepwise increase of model dimensions. In the $3 \mathrm{D}$ project management, a bunch of functions could be achieved simultaneously, including visualized bidding management, an enterprise level of quota management, and life cycle process management. In addition, this study demonstrates that the assignment of the core positions of the BIM team in the project management team structure is the key to the success of the 7D BIM implementation, which provides significant implications for future BIM management. Last but not least, this study proves that the integration of Internet of Things (IoT) into the 7D BIM makes great contributions to the facilitating of information collection and communication in the project, which should be the future direction of BIM implementation. This paper is organized into the following sections: Section 2 presents the literature review on BIM modeling; Section 3 illustrates the development of a 7D BIM, with details on each dimension and its operation; Section 4 demonstrates the implementation of the proposed 7D BIM, where a complex project launched in China is analyzed; Section 5 discusses the characteristics, merits, limitations, and performance of the 7D BIM; and Section 6 presents the conclusion of this paper.

\section{Literature Review}

Along with the development of BIM technology and software, the BIM applications have transformed from 3D based applications to $\mathrm{nD}$ based applications. In the early stage of 3D based applications, 3D BIMs were mainly applied in the design and operation phase to stimulate energy consumption, facility performance, evacuation procedures, operation management, and maintenance [20]. 3D models essentially facilitated collaboration between architects and structural engineers; thus, redesigns, processing, revisions, and changes were reduced [21]. Most of the academics and practitioners agreed that a $4 \mathrm{D}$ BIM was related to time (or planning or scheduling) [22]. Nevertheless, the applications of $4 \mathrm{D}$ BIMs were diverse. For instance, Zhang and $\mathrm{Hu}$ [23] defined 4 levels of 4D BIM: the first level was a simple combination of 3D model and schedules, then construction activities and resources (labor, materials, and machinery) were imported into the second level, and the third level was an extension of site entities, while the structural information of mechanical analysis was further augmented in the fourth level. The key benefit of the 4D BIM was the contribution to risk mitigation by improving team coordination [24]. It was proved by Sloot et al. [25] who adopted the 4D BIM to realize the function of risk mitigation strategies by evaluating design and process, checking workflow clashes and task dependencies, and optimizing construction logistics. Su et al. [26] embedded geometric information, material properties, and a construction schedule in the 4D BIM. From an environmental perspective, the 4D BIM in Jupp's study [27] included the function of construction planning, construction scheduling, production control, on-site management of safety, workspaces and waste, and environmental planning and management. Guerra et al. [28] further extended the 4D BIM to emphasize construction waste management, construction waste reuse and recycling, resource recovery, onsite reuse, and off-site recycling. Logistics planning and control at different hierarchical levels could also be carried out with the support of 4D BIMs [29].

Researchers and practitioners also had consensus about the extension of the 5D BIM to cost $[21,22,30]$. The 5D BIM integrates all of the cost information data such as quantity, schedules, and price, which was useful in the early design stage of a project as well as later during the construction in which changes may occur [24]. The 5D BIM could provide real-time cost advice throughout the detailed design, construction, and operational stages, which helped place the project cost manager at the top of the "value chain" for project clients [30]. The application of 5D BIM effectively improved the level of meticulous management in the construction stage, reduced project waste, and ensured construction quality [31]. However, beyond the fifth dimension, there appears to be a lack of agreement in BIMs. Sustainability, facility management, safety, health, energy, project life cycle, procurement, knowledge, and as-built operation were popular dimensions of $6 \mathrm{D}$ and $7 \mathrm{D}$ BIMs [21, 22, 30, 32-37].

By developing and implementing $\mathrm{nD}$ BIMs, various functions and benefits could be achieved in different phases of construction projects. For instance, BIM could simplify the data collection process and support dynamics life cycle assessment [26]. BIM could significantly reduce the time needed for the LCA applications due to the automatic and accurate generation of the bill of material quantities [24]. BIM could also be integrated with Internet of Things (IoT), which enabled a continuous flow of real-time data and represented a wide range of valuable information [24]. The real-time data from the IoT devices was a powerful paradigm to improve construction and operational efficiencies [33]. Zhai et al. [38] further demonstrated that the combination of BIM and IoT could overcome the barriers that hamper the possible function of BIM, including inconvenient data collection, lack of automatic decision support, and incomplete information. By providing information needed for energy performance evaluation and sustainability 
assessment, BIMs enable integrated design, construction, and maintenance towards Net Zero Energy buildings [39]. BIM also improved the efficiency of facility management and project management performance by sharing and exchanging building information between different applications throughout the life cycle of the facilities [40-42]. The integration of BIM into the project execution planning ensured greater control over the model, which helped prevent time and cost inefficiencies, facilitate the execution of relevant tasks, and make the whole process efficient including design, construction, and operation [24, 43, 44]. All construction activities were involved in the proposed BIM, therefore supporting the dynamic structural safety analysis and improving the project's safety performance [23].

In summary, various $\mathrm{nD}$ BIMs have been developed and applied in the construction industry to facilitate different functions and improve management efficiency in construction projects. However, $4 \mathrm{D}$ and $5 \mathrm{D}$ models were still the most popular and common BIMs. In addition, the experiences of 6D and 7D BIM development and application were inadequate, especially in complex projects. Thus, this study presents a 7D BIM to promote the efficiency of the construction process and reduce the cost during the life cycle of a complex project.

\section{Development of 7D BIM}

3.1. Framework of $7 D$ BIM. In order to achieve the best function of the BIM, a BIM management mechanism is firstly established (depicted in Figure 1). In the primary level, the BIM team is set as the coordinator and the BIM manager is assigned to directly respond to owners' enquiries. Designers, general contractors, professional subcontractors, supervisors, consultants, and other participants are connected by the BIM platform for collaboration. The second level of collaboration lies in coworking on tasks in the construction process and maintenance. In this BIM management system, the general consultant of BIM could guide and coordinate the application of BIM technology in the whole process of the project.

Under the BIM management and collaboration mechanism, the framework of the 7D BIM could be established (presented in Figure 2). It contains a traditional 3D BIM, a $1 \mathrm{D}$ schedule management model, and a $3 \mathrm{D}$ project management model (including bidding management, enterprise quota management, and process management). The 3D BIM is developed by combining architecture model, structure model, equipment model, steel framework model, and other solid models. By combining the 3D BIM with the $1 \mathrm{D}$ schedule management model, a 4D BIM is developed, which is consistent with previous studies. Afterwards, the 3D project management model is integrated with the $4 \mathrm{D}$ BIM, thus forming the 7D BIM.

3.2. 3D BIM. Consistent with other studies, the 3D BIM in this study is also a visual expression of engineering information. By applying the following Work Breakdown Structure (WBS) process, the task nodes of engineering based on 3D BIM construction model can be defined, broken down, and structuralized:

(1) Each task in WBS should be described independently and would not be implemented repeatedly.

(2) The state of progress and completion of each task in WBS should be quantified and be consistent with the actual work.

(3) The tasks in WBS need to be gradually decomposed into subtasks, according to a certain relationship within the scope of the project.

The logical relationship among components of the 3D BIM, node tasks in WBS, and construction resources is depicted in Figure 3. As can be seen, there are cross correspondents among work tasks in WBS and construction resources. Thus, WBS plays an important role in construction schedule management, resource supply, purchase, and project implementation.

The 3D BIM is built by applying the Autodesk Revit 2018 software, through which independent BIMs such as architecture model, structure model, water supply model, heating system, electricity model, and general drawing model are developed according to their specialty. These professional models are then integrated into a document for an overall analysis and application. Software solutions including AutoCAD 2014 and Autodesk Navisworks 2018 are utilized in this process for the design work (consultation and exchange of project design drawings), clash detection, visualization, dynamic simulation, and other project evaluation (shown in Table 1). The software can be replaced by other approaches if their interfaces are compatible with Revit.

3.3. Schedule Management Model. Based on the simulation results, the 3D BIM can be integrated with the $1 \mathrm{D}$ schedule management process, by which the $4 \mathrm{D}$ BIM is built to provide a visualization expression of the construction process. The integration process imports a project schedule (MS Project, Excel schedule) into the 3D BIM by the schedule management software imbedded in the BIM system. The flow chart of this process is shown in Figure 4.

Multidimensional construction management can be realized in this $4 \mathrm{D}$ model. The $3 \mathrm{D}$ virtual construction, animation display, resource allocation (manpower, materials, mechanical equipment), cost, and safety information are integrated with the budget and working procedure. This would provide engineers/owners with essential information for the corresponding fund preparation. Meanwhile, the simultaneous visualization function enables stakeholders to view and monitor project progress, capital plans, WBS, machine plan, and other information anytime and anywhere. With real-time display of project planning progress and actual progress in the 4D BIM, problems can be detected as early as possible and the operation of the project could be facilitated.

3.4. 3D Project Management Model. Instead of stepwise adding the BIM from $4 \mathrm{D}$ to $7 \mathrm{D}$, this study develops a package of a $3 \mathrm{D}$ project management model to monitor the 


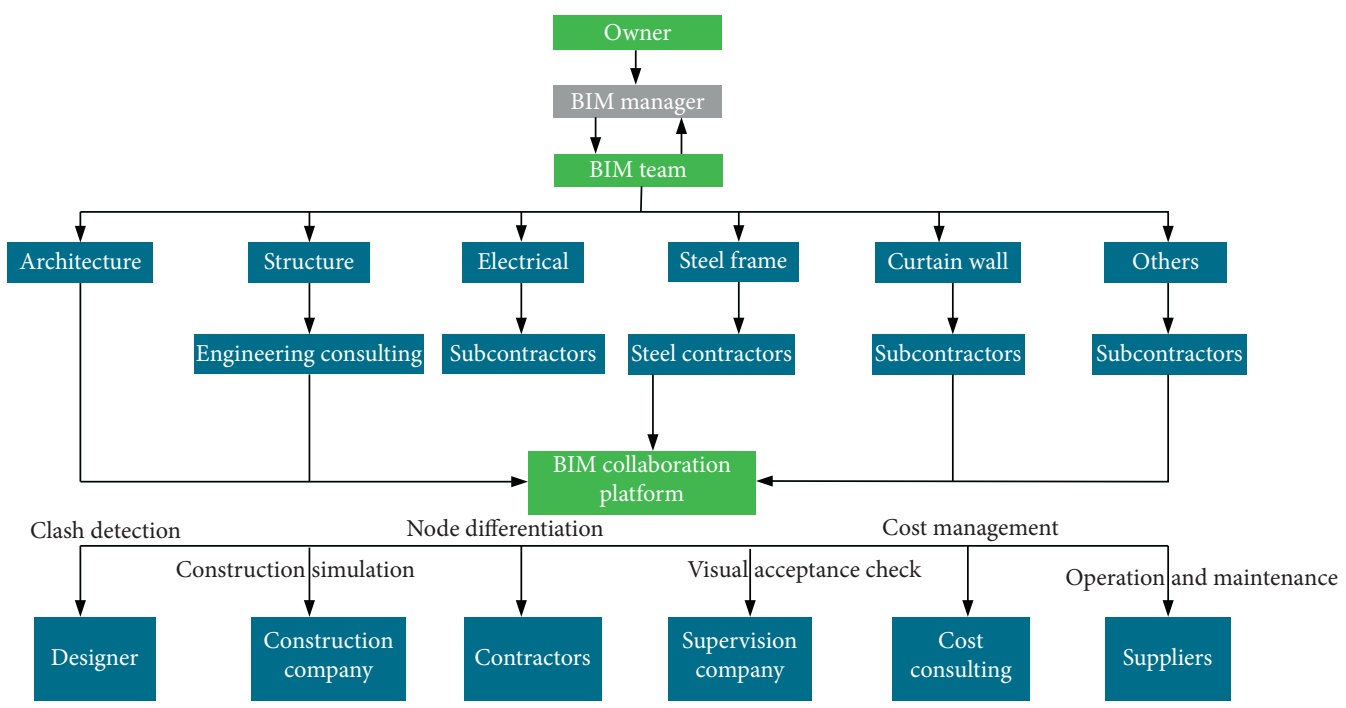

FIgURE 1: The design flow chart of BIM management for owners.

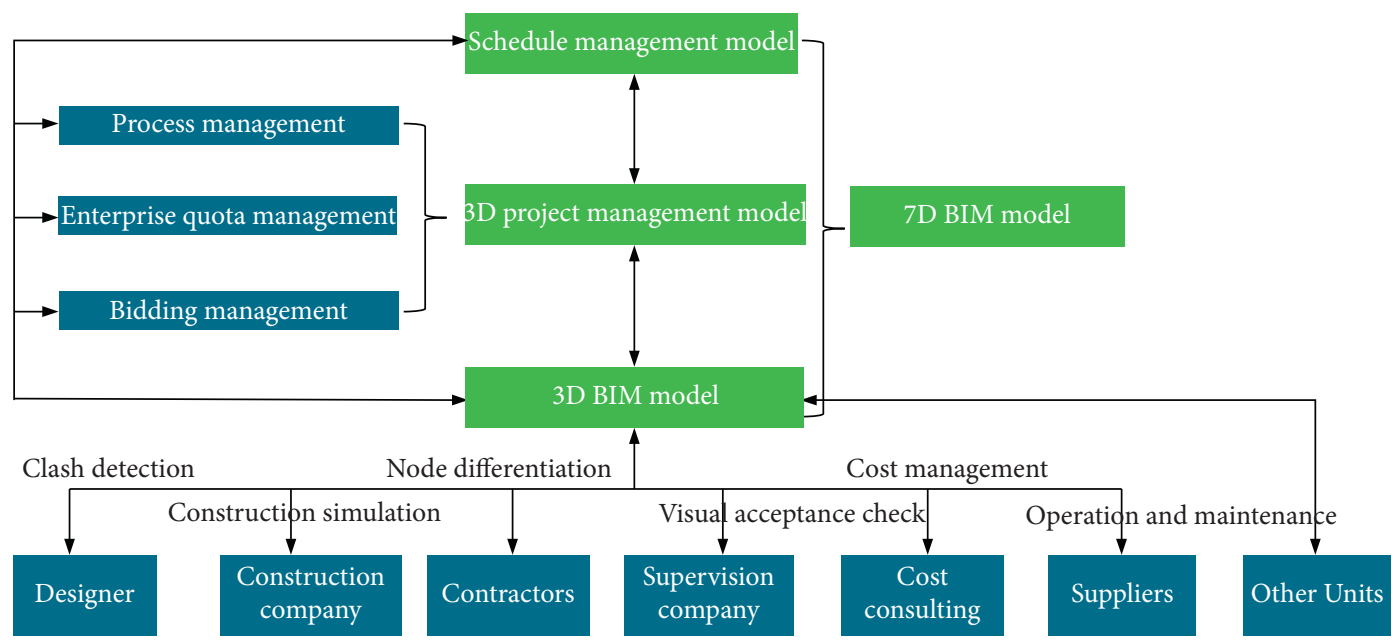

Figure 2: General framework of the 7D BIM.

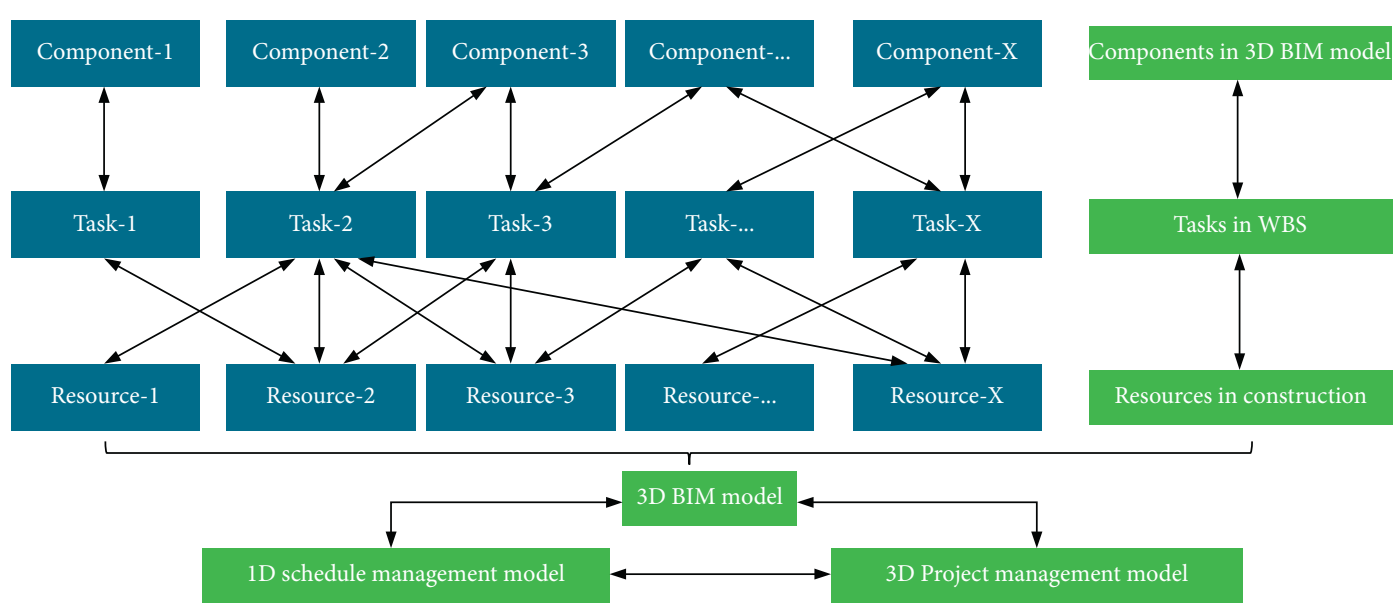

FIGURE 3: A typical logical relationship in WBS. 
TABLe 1: BIM software.

\begin{tabular}{|c|c|}
\hline Software & Function \\
\hline Autodesk Revit 2018 & $\begin{array}{l}\text { Building, structure, mechanical, and electrical professional modeling software; creating three-dimensional } \\
\text { model of the project, collaborative management, project data }\end{array}$ \\
\hline Luban Works & Integrated BIM software for multidimensional BIMs \\
\hline AutoCAD 2014 & Carrying out design work, consultation, and exchange of project design drawings \\
\hline Autodesk Navisworks & Clash detection, 3D project coordination, 4D planning, visualization, dynamic simulation, and other project \\
\hline 2018 & evaluation and audit software \\
\hline HiBIM & Plug-in software based on Revit, to improve work efficiency \\
\hline Fuz & Mobile project review software based on Revit \\
\hline Enscape & Simultaneous rendering plug-in software based on Revit \\
\hline
\end{tabular}

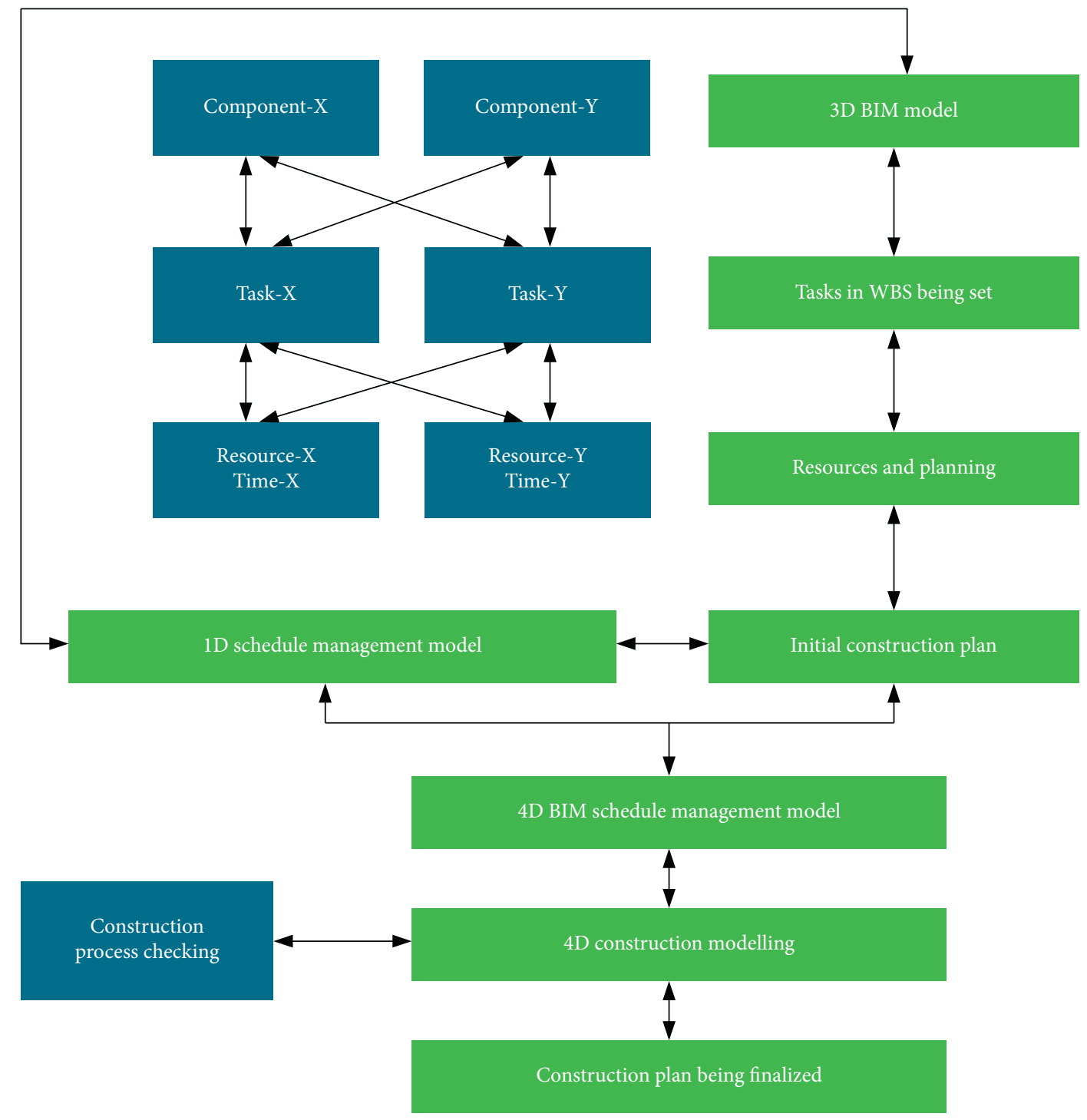

FIgURE 4: Flow chart of 3D BIM combined with 1D schedule management model.

project's construction process. Three main phases or dimensions are covered in the package: the bidding management model, the enterprise quota management model, and the process management model (shown in Figure 2). The functions and mechanisms of the models are discussed below. 
3.4.1. Bidding Management Model. Traditional bid preparation and evaluation require massive document work and intensive labor input. To improve the efficiency of the bidding process, this study proposes a bidding management model by integrating project cost and schedule with project information in the 3D BIM. With visualized business and technical and price standards, the accuracy and professionalism of bidding can be significantly improved. The bidding management model and workflow chart are shown in Figure 5, and the features of steps and components are presented below.

(1) Participants: Based on the project management process and the system investigated through WBS in the 3D BIM, the bidding tasks for the general contractor, supervisors, and cost consultants of the project are specified. Those who have completed the bidding can resubmit the technical applications in BIM to other potential project participants.

(2) Designing BIM bidding files: The content, format, and preparation methods for designing BIM bidding files are specified in the bidding model, including the 3D BIM, software, modeling content, and application scope. In addition, the modeling accuracy requirements for each design phase are also quantified, including 3D BIM viewpoints, BIM bidding tools, number of viewpoints, display content, remarks, roaming animation, and landmark models.

(3) Basic price: In the bidding model, the basic engineering data of BIM can be investigated before the bidding process, thus increasing the data accuracy and reducing the probability of unbalanced bidding. In the procedure of bidding evaluation, the basic price of the bid can be checked and problems corresponding to the quantity of engineering or unreasonable comprehensive price can be avoided.

(4) Bidders: To successfully establish the bidding model, bidders have to prepare and submit the BIM bid documents as required, where the function of the software for BIM tender should be clarified. Specifically, the utilized tools should fully support the conversion of BIM modeling software (mainstream), where the IFC format can be converted into GMS format and integrated with other model files. In addition, the data exchange standards of BIM viewpoint, landmark model, BIM bid, and other related files should meet the required standard.

(5) Bidding process: The developed BIM bidding model can support the evaluation of BIM implementation plans, BIMs, previews, roaming animations, integration with surrounding environment, and supporting BIMs by different bidders. This platform can also allow experts to view similar projects (winners' bids) and historical winning bids of tenderers, thus finalizing the bidding process with a reasonable evaluation.
3.4.2. Enterprise Quota Management Model. The cost dimension (5D) of BIM is achieved by a quota management model in this study. It refers to the cost management of construction enterprises, where the cost of labor, materials, machinery, and other expenses can be calculated through pricing software. Luban Works (software) has been adopted in this study to summarize the project construction cost by applying the corresponding project norms and quantities. The proposed quota management model is aimed at controlling the cost based on the 3D BIM, schedule management model, bidding management model, and process management model. The flow chart of the enterprise quota management model is demonstrated in Figure 6.

Note that, during the construction process, some alternations may occur and lead to price fluctuations. For example, the outbreak of COVID-19 and the correspondent lockdown policy in early 2020 caused a shortage of labor and materials in most construction projects, which led to an increase in the price of raw materials and manpower. With the help of BIM platform, the price fluctuations can be reflected in the quota management model and reported to owners and BIM managers. The owners then could carry out a contingency plan to minimize the impact induced by alternations, thus controlling the project cost through an efficient way.

3.4.3. Process Management Model. This study establishes a process management model to achieve multiple functions of the integrated BIM. It is developed by establishing a BIM based process database and then connecting the database with on-site management (Figure 7). The project working procedure database is developed by specifying a standard working procedure for the decomposed working unit (tasks in WBS) with the help of the 3D visualization BIM. This means that every working procedure is predefined and modeled in the 3D BIM to secure its reliability, efficiency, and quality. Considering the fact that some special requirements would be emerging in the construction process and on-site work, the working process database can be updated or renewed by adding modifications to existing standard procedures. Through this visualized approach, the construction personnel can understand the technical details in civil engineering, mechanical work, electrical work, decoration, etc.

The development of working process database in BIM platform enhances the on-site management through interrelating the standard working process to corresponding BIM components, procedure management, cost control and resource management, etc. Verified by the standard working process, the project schedule and dynamic cost management can be simulated, controlled, and modified. In addition, the site layout and management can be deduced and optimized from the process level. This also would help project owners/managers analyze the application effect of BIM process library in the end of the construction process. 


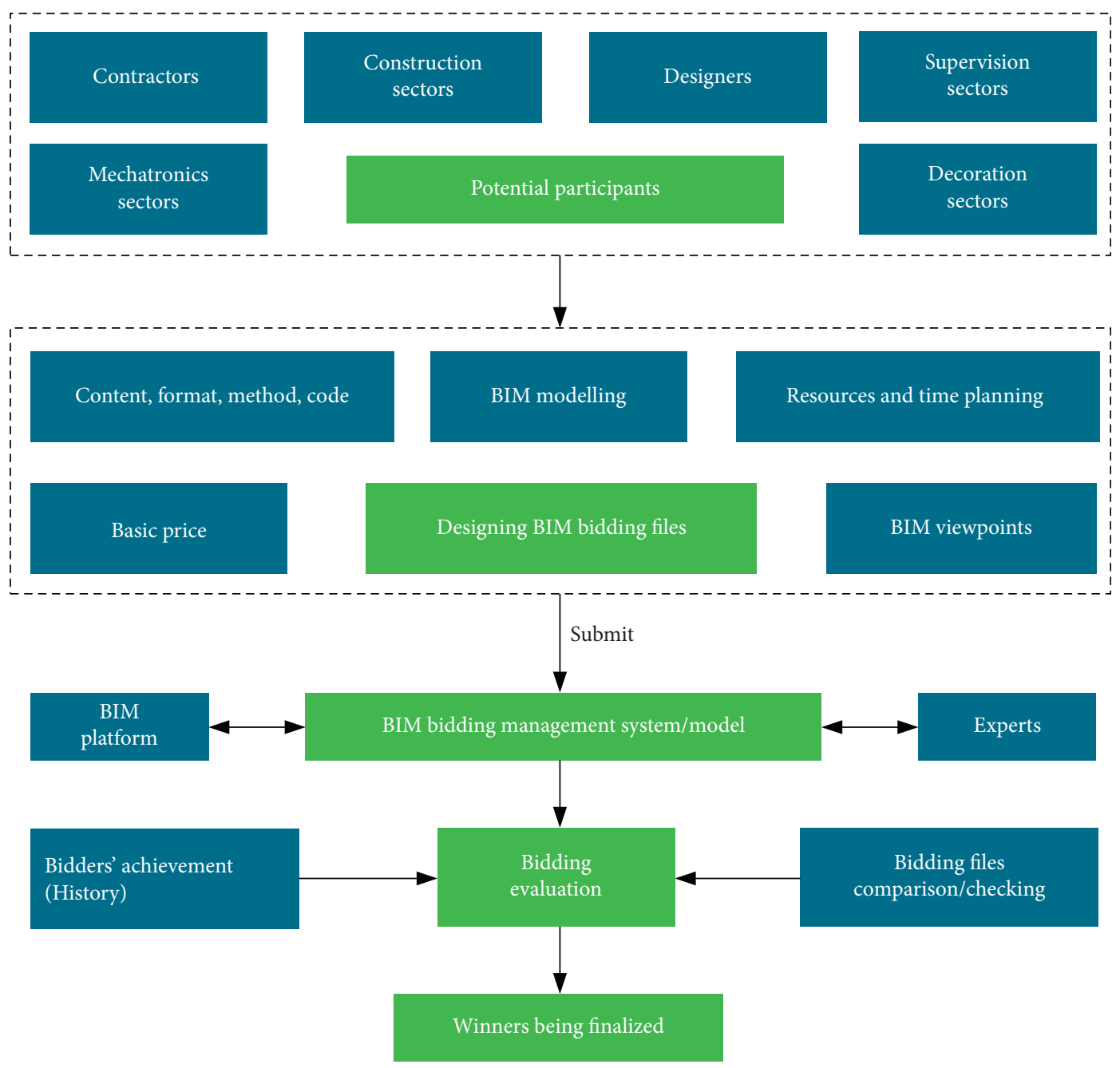

Figure 5: Flow chart of bidding management model.

\section{Implementation of 7D BIM}

4.1. Background of the Project. A large-scale comprehensive modern project located in the western region of China, Phase X project, has been taken as an example for the demonstration of the performance of the proposed 7D BIM. This project contains multifunctional facilities including offices, international conference center, brand business, star hotel, cultural and entertainment center, and industry park. The main structure of this complex building combines a slab-type building (5 layers, 20-meter high) and a tall tower with a height of over 200 meters, covering a total construction area of 1.4 million square meters. The encountered difficulties include complex design, comprehensive working procedures, and high project implementation risk. Thus, the traditional operation process and technical measures cannot meet the requirements of this complex project. The 7D BIM is adopted to improve the life cycle management of the project to achieve the objectives of low cost, high efficiency, environmental friendliness, high quality, safe and modern operation, etc.
4.2. 3D BIM and Its Application. The first step of this project is to recruit a BIM manager and his team members, so that a unified BIM working team can be assembled to work for the owner. The main structure of this BIM management team is shown in Figure 8, among which the BIM manager supervises BIM modeling team, BIM verification team, BIM application team, and BIM on-site consultant. Tasks and responsibilities for each member and subteam of the BIM management are specified. Then, the 3D BIM is developed through the collaboration flow chart shown in Figure 9, including the project librarian, project technician, BIM modeling engineer, BIM audit engineer, and modeling technician. Based on the collaboration work, the 3D BIM platform of the project is established, which is depicted in Figure 10. Within this 3D BIM, submodels based on their specialties can be built in the 3D BIM platform, such as the curtain wall model, the steel structure model, the overall construction model, the mechatronic model, water supply and drainage model, weak/strong-current model, firefighting model, and heating and cooling model (presented in Figure 11). All submodels built in the 3D BIM platform can 


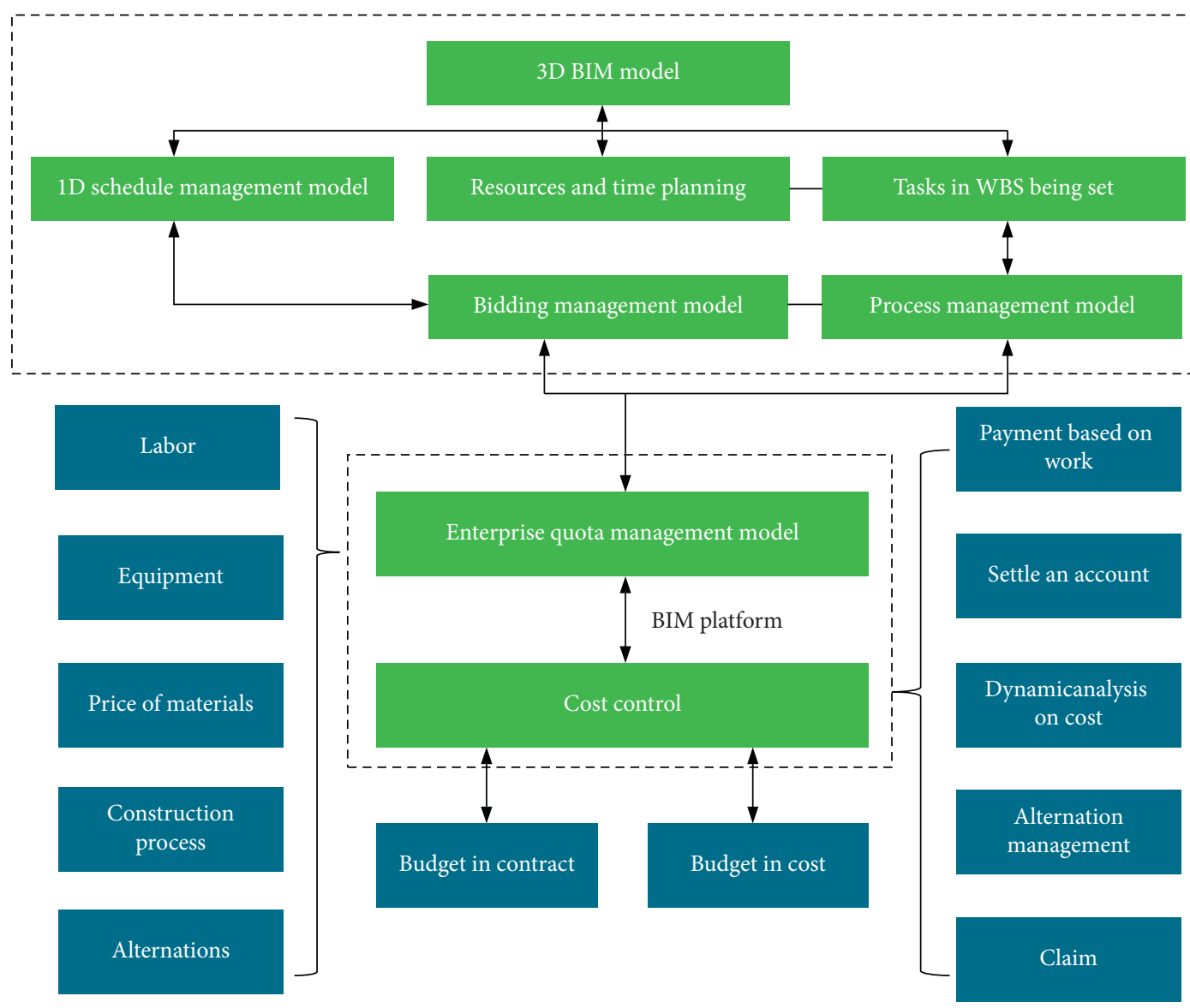

FIGURE 6: Flow chart of enterprise quota management model.

be visualized, modified, and verified through clash detection and modeling, the procedure of which has been presented in Figure 12. In addition, the accuracy of these submodels in the BIM platform can be enhanced by giving more details for analysis and simulation, and some examples of refined submodels are shown in Figure 13.

This visualized process would help reduce project cost and shorten timelines. In the design stage, it is possible to create difference scenarios in the 3D BIM by carrying out various building models, restoring design schemes, conducting real-time scheme comparison and intelligent analysis, and implementing modifications and other functions, thus improving the design efficiency. In the construction stage, the $3 \mathrm{D}$ BIM is connected with the BIM project management, so that the construction progress, cost, and quality can be monitored. For example, the clash detection can be carried out before construction, while the construction process can be visualized (Figure 14).

4.3. Schedule Management. The $4 \mathrm{D}$ schedule management $\mathrm{BIM}$ for Phase $\mathrm{X}$ is developed by integrating the 3D BIM with the $1 \mathrm{D}$ schedule management model. In the 4D BIM, virtual construction, animation display, resources (manpower, materials, mechanical equipment) allocation, cost, and safety information involved in the construction process are deeply integrated with the budget and working procedure. As shown in Figure 15, the modeling progress, capital plan, and field progress of Phase X can be visualized simultaneously in the 4D BIM. Project progress, capital plan, WBS, mechatronics plan, and other information can also be viewed, thus securing the construction schedule of this project. For better communication between all participants, the Internet of Things has been adopted in the schedule management model through installing sensors, monitoring devices, cameras, and advanced communication devices. With the help of the IoT, the on-site monitoring work can be viewed on cell phones, pads, BIM platform, and PCs anytime and anyplace. In addition, through advanced communication technology, real-time on-site construction control can be realized (Figure 15).

\subsection{D Project Management}

4.4.1. Bidding Management. The bidding management model plotted in Figure 5 is adopted in this project to manage the bidding process. In the preparation stage, the BIM management team drafts BIM bidding documents for the architecture model and calls for potential designers to bid for this project. Bidding documents for other work such as construction, mechatronics installation, equipment, suppliers, and contractors are also drafted and specified in the BIM platform. In the bidding process, BIM based 


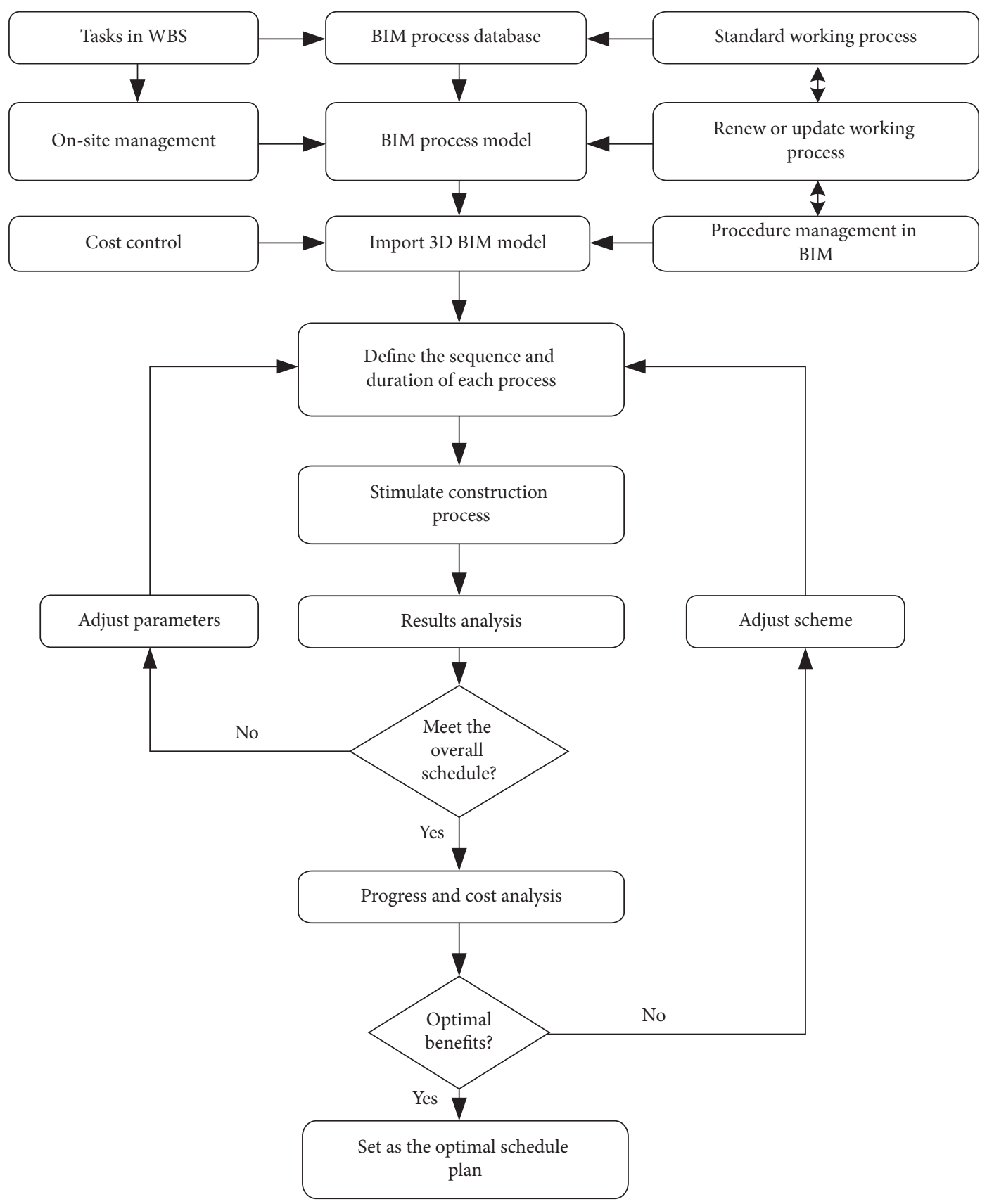

FIGURE 7: Flow chart of process management model.

bidding documents are prepared by potential bidders and submitted to the BIM bidding management system, according to BIM standards and requirements. In the bid opening stage, the BIM bid documents submitted by the bidders are checked by the tenderer or the bidding agent. Then, these double-checked BIM bids are evaluated by BIM experts through the BIM based bid evaluation system. With the advantage of BIM visualization, experts can review the integrity and accuracy of the model by $3 \mathrm{D}$ roaming (shown in Figure 16) among individual and professional components in BIM bid documents. In addition, with the visualized bidding management model, BIM teams can quickly and accurately compile the bill of quantities, thus providing reliable data support for bidding accounting and reducing the risk of unbalanced bidding. In the decision stage, the Bid Committee reviews the evaluation report on BIM bid and bid documents (BIM, filed layout, cost, procedure management, process management, suppliers, reputation, etc.), based on which the bid decision would be finalized.

4.4.2. Enterprise Quota Management. Considering various factors affecting the level of quota, an enterprise quota management model is developed based on the flow chart shown in Figure 6. A thorough investigation is carried out by the BIM team to make a scientific analysis of the enterprise 


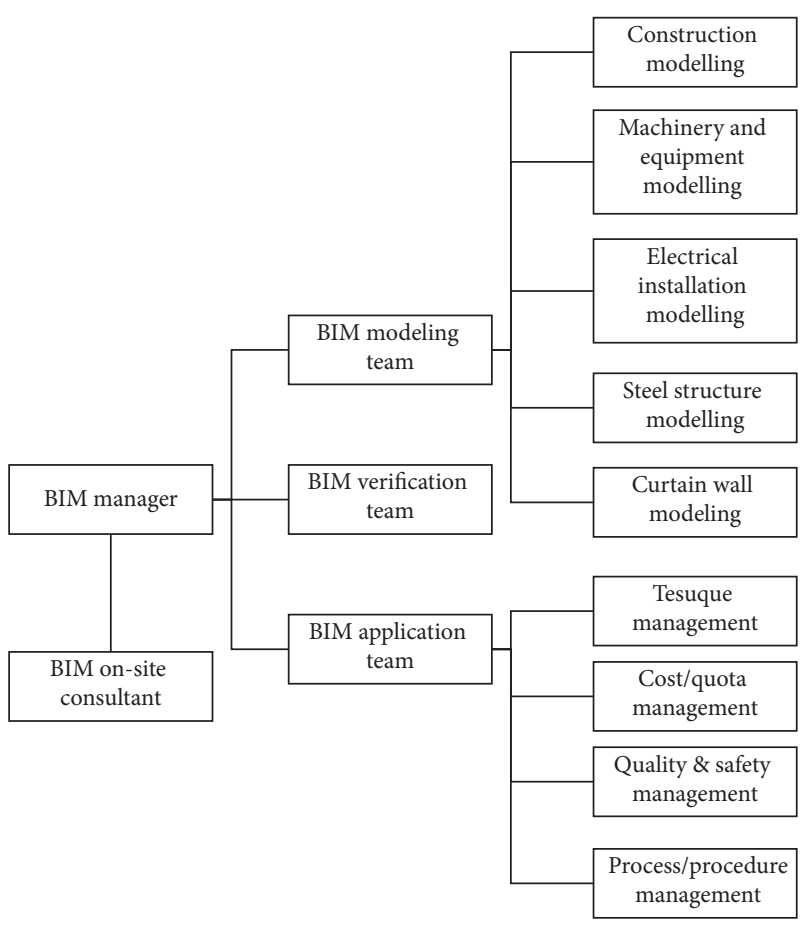

FIgURE 8: The structure of a BIM management team.

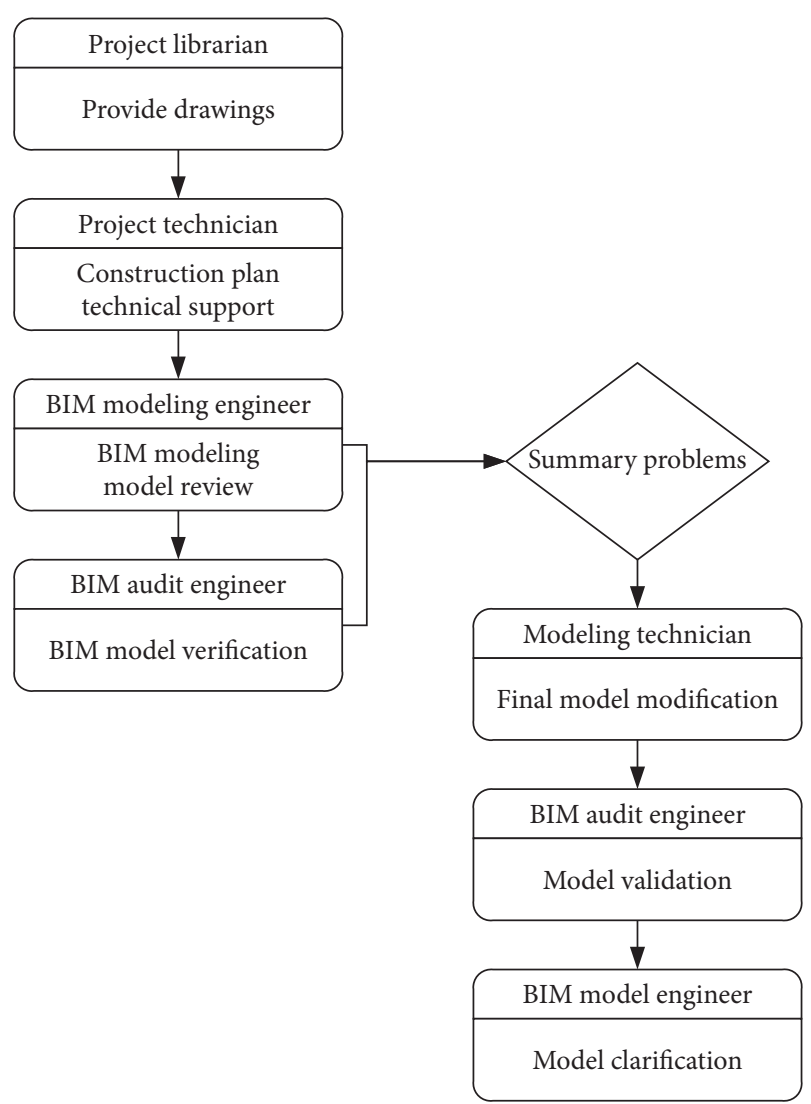

Figure 9: The flow chart for the development of 3D BIM.

production and operation. By analyzing and calculating all aspects of consumption data, a reasonable standard of quota is determined in the BIM system. In addition, the level and

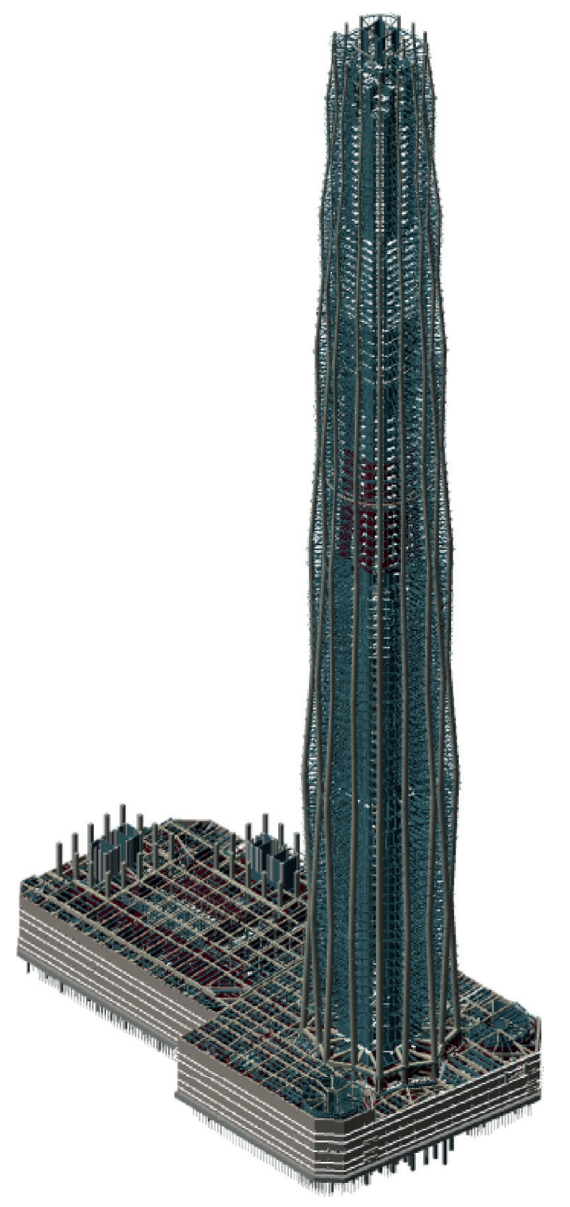

FIgure 10: The developed 3D BIM platform.

scope of the quota are balanced by adopting effective technical measures (e.g., marketing/historic investigation, surveys on similar projects, nearby construction, and suppliers) to ensure the implementation, inspection, evaluation, and count of the quota. The cost of labor, material, and machinery usage and other expenses can be calculated through Luban Works. As shown in Figure 17, the corresponding project norms and quantities can be calculated during the construction process. The total/final project construction cost can be controlled by the enterprise quota management model based on the 3D BIM, schedule management model, bidding management model, and the process management model.

4.4.3. Process Management. The BIM based process database and its connection/interaction with on-site management are developed according to the demonstration in Figure 7. In the BIM based process database, every working procedure is predefined and modeled in the 3D BIM. Typical standard procedures covered in the process management model include site clearance, open-pit excavation, open-pit support, back fill, framework engineering, steel work, concrete work, embedded work, scaffold work, temporary elevation work, masonry work, mechatronics work, and decoration work. For the 


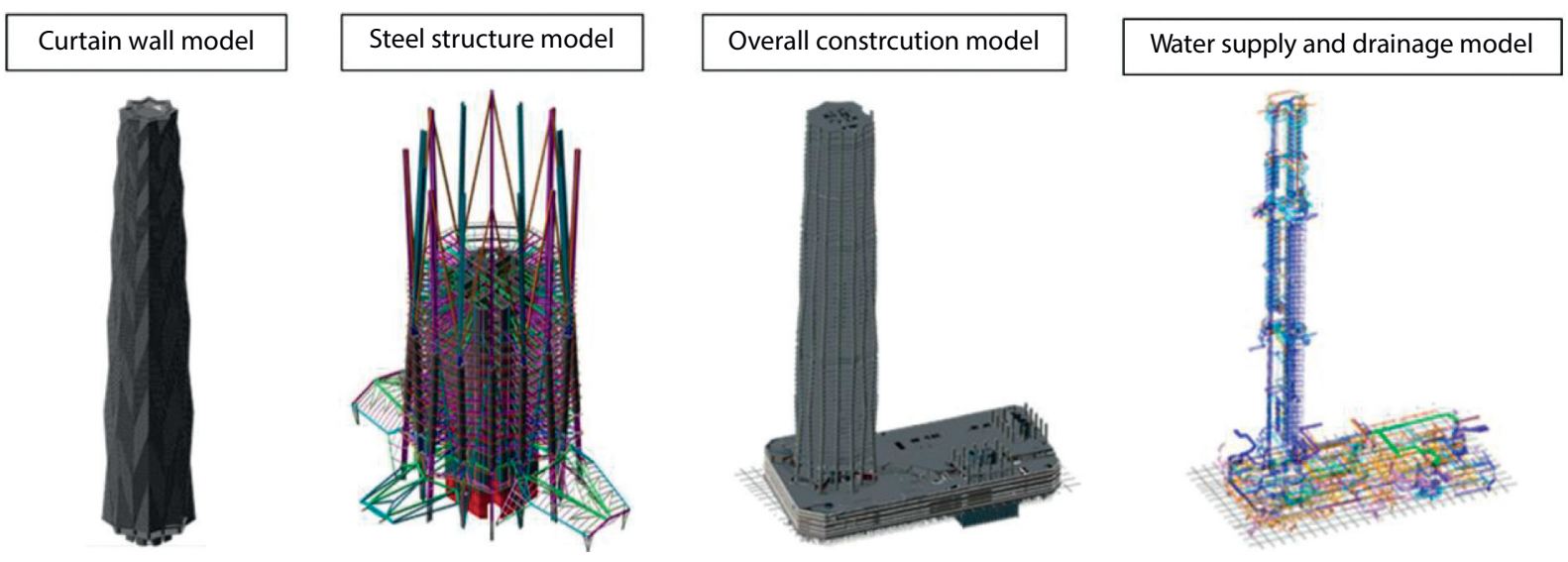

Figure 11: Submodels built in the 3D BIM platform.

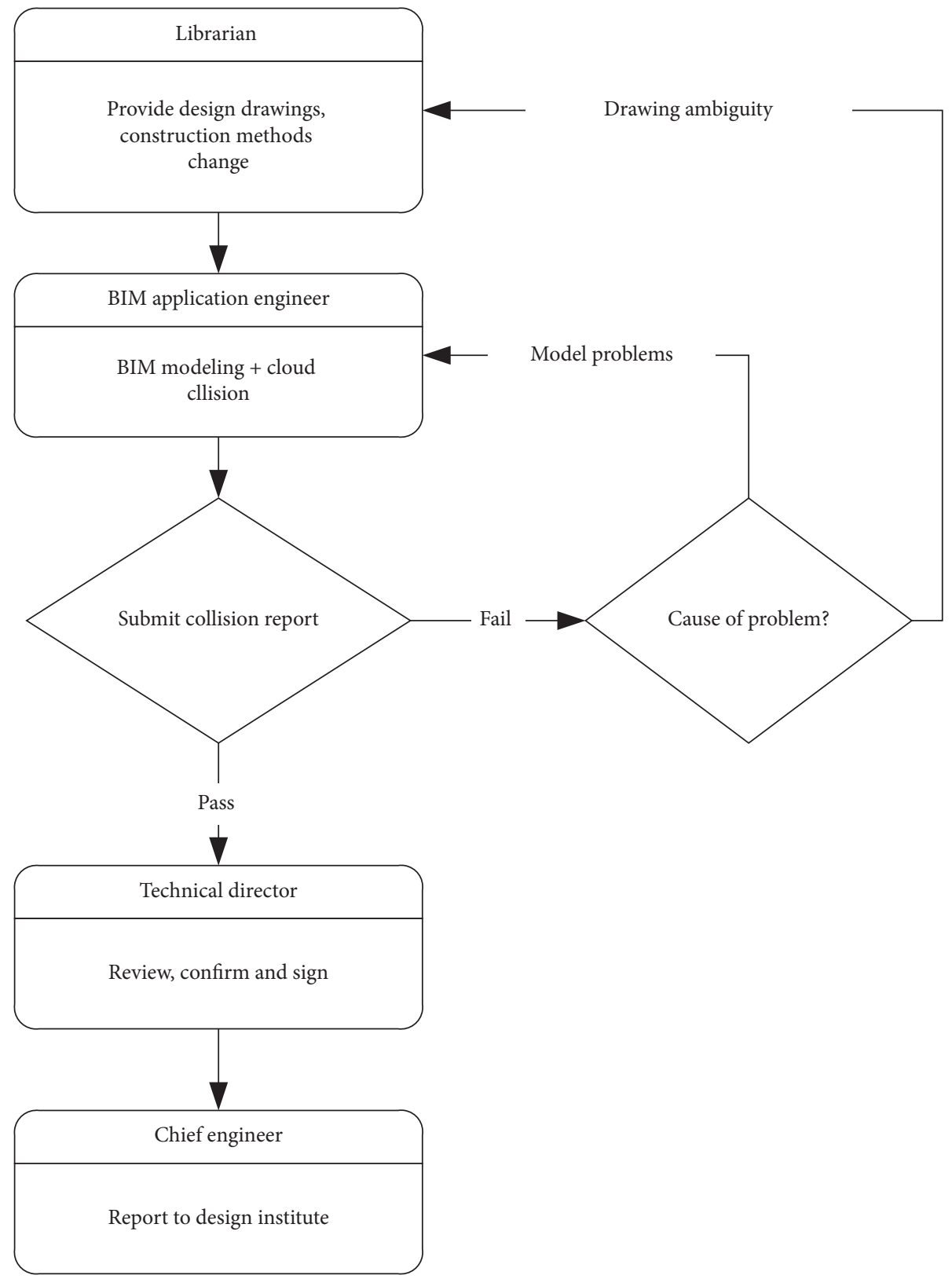

FIgURE 12: The application procedure of 3D BIM. 

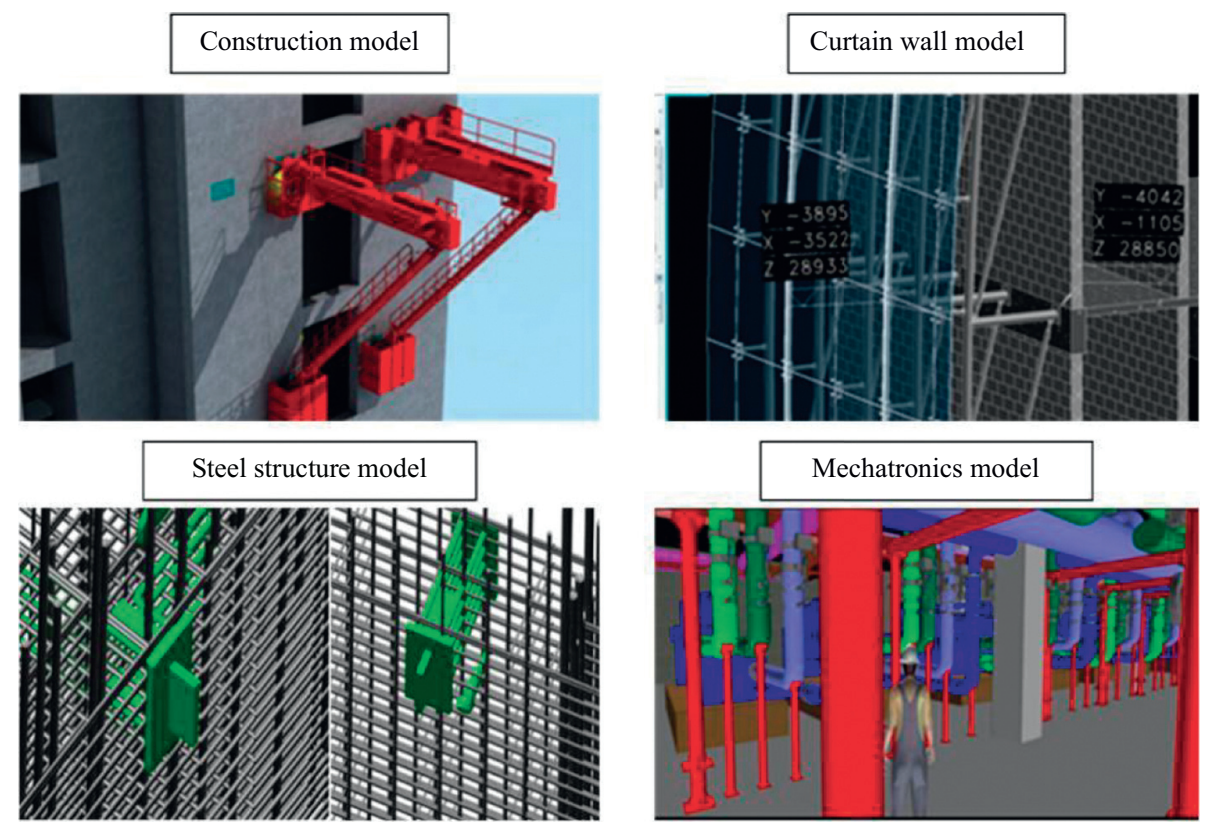

Figure 13: The refinement of some 3D submodels.
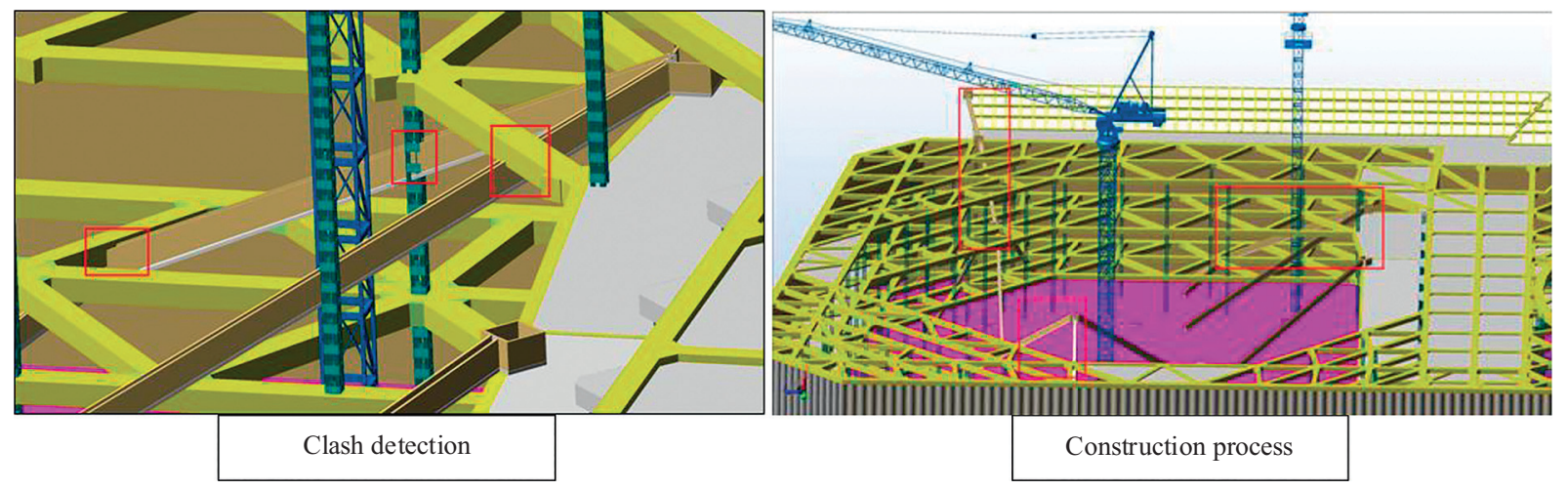

Figure 14: Clash detection and construction process modeling in 3D BIM.

consideration of special requirements for tall building construction, a few new working processes and modifications towards existing procedures are added to assist process management. For example, the automatic elevation system for scaffolding is taken into account in the design of the $3 \mathrm{D}$ structure model. Precast connections are made for each layer of the tall tower part; thus, the drilling/installation scaffolding track on the main building can be saved. Internet of Things is integrated with the process management model by installing and embedding of many advanced sensors/monitors/cameras, communication devices, and related products to the BIM platform. With the help of advance technology in information collection and real-time communication, BIM team members can check the work on site and visualize the BIM process, and the construction personnel can understand the technical details on civil engineering, mechanical work, electrical work, decoration, etc. (shown in Figure 18).
4.5. Overall Performance of the Developed 7D BIM. The developed 7D BIM is implemented by the BIM team to assist the construction of Phase $\mathrm{X}$ project. After receiving the first version of the designed construction drawings on August 10, 2015, the BIM consulting team organized and evaluated the drawing integrity and modeling conditions within 20 days, and feedback was sent to the client technical director and head of the Design Institute. Then the BIM team started the BIM modeling work on September 9 and finished the professional BIMs in about 3 months. The precision of important component/equipment models reached LOD 400, while the important operation/maintenance models reached LOD 500, corresponding to the requirement of construction deepening design, building operation, and maintenance management.

In the bidding process, stakeholders including construction companies, contractors, and equipment suppliers were called to submit their bids to a well-developed BIM 

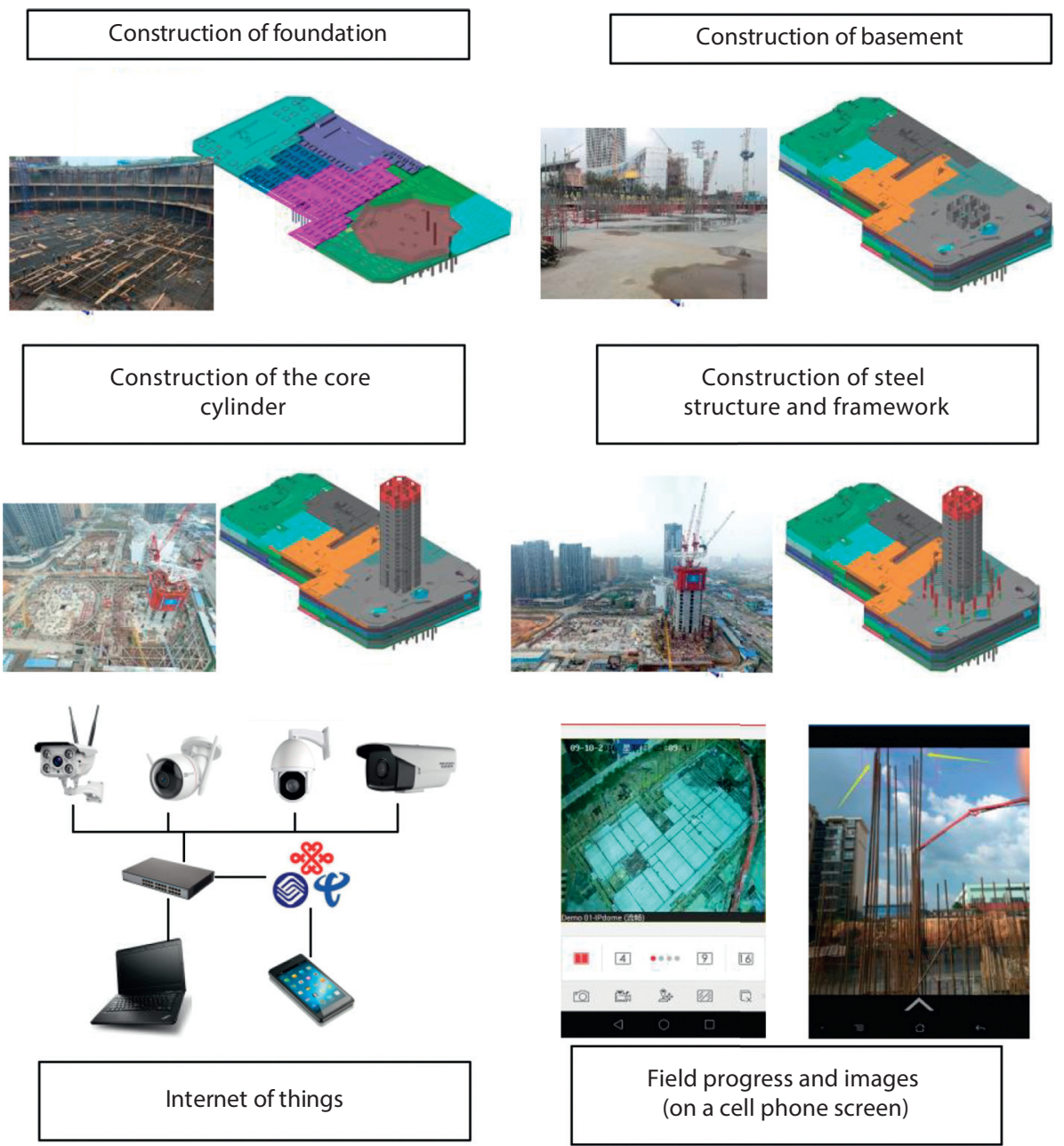

Field progress and images

(on a cell phone screen)

FIGURE 15: The modeling progress, capital plan, and field progress of the project in BIM platform.

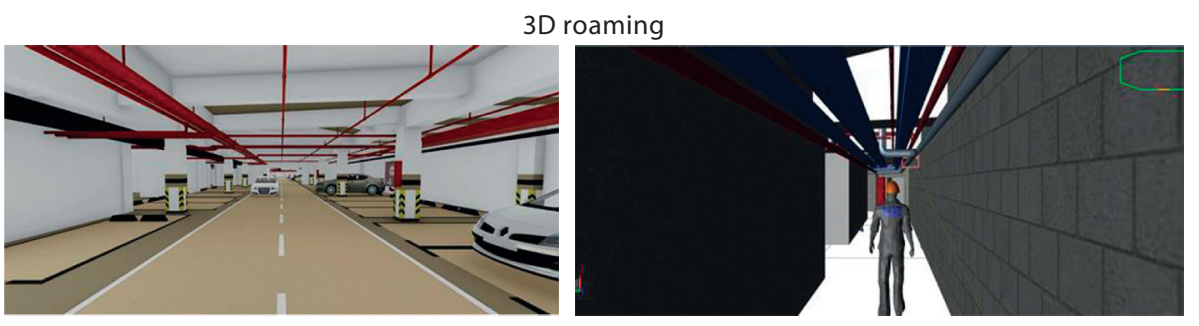

FIgURE 16: 3D roaming in BIM bid.

bidding management system, within which models, quality, costs, process, and procedures could be visualized and compared. More than 20 bidding activities were launched during the construction process. The bidding averagely lasted for around 40 days, which achieved $30 \%$ of the bidding time savings compared to the traditional bidding process. In addition, the decisions based on BIM bidding system were more precise and comprehensive, as stated by the chief bidding expert.

In the design stage, the entire professional BIMs were virtually built. Based on BIM modeling, the defects of design and construction drawings of various specialties were detected. During the examination, 1858 defects were found, including 661 in the architecture and structure models and 1197 in the mechatronics model. Clash detection was also conducted, where around 58 clash points were found by the $3 \mathrm{D}$ BIM. Each collision point was shown in a $3 \mathrm{D}$ graphics display, namely, collision position, collision pipeline information, and the corresponding drawing position. With the efforts of defect investigation done in the design stage, many construction/installation problems were avoided in the construction process.

In the construction process, the $4 \mathrm{D}$ BIM procedure management model was applied to manage the WBS progress, capital plan, manpower, mechatronics plan, etc. With real-time display of project progress, the planed and 


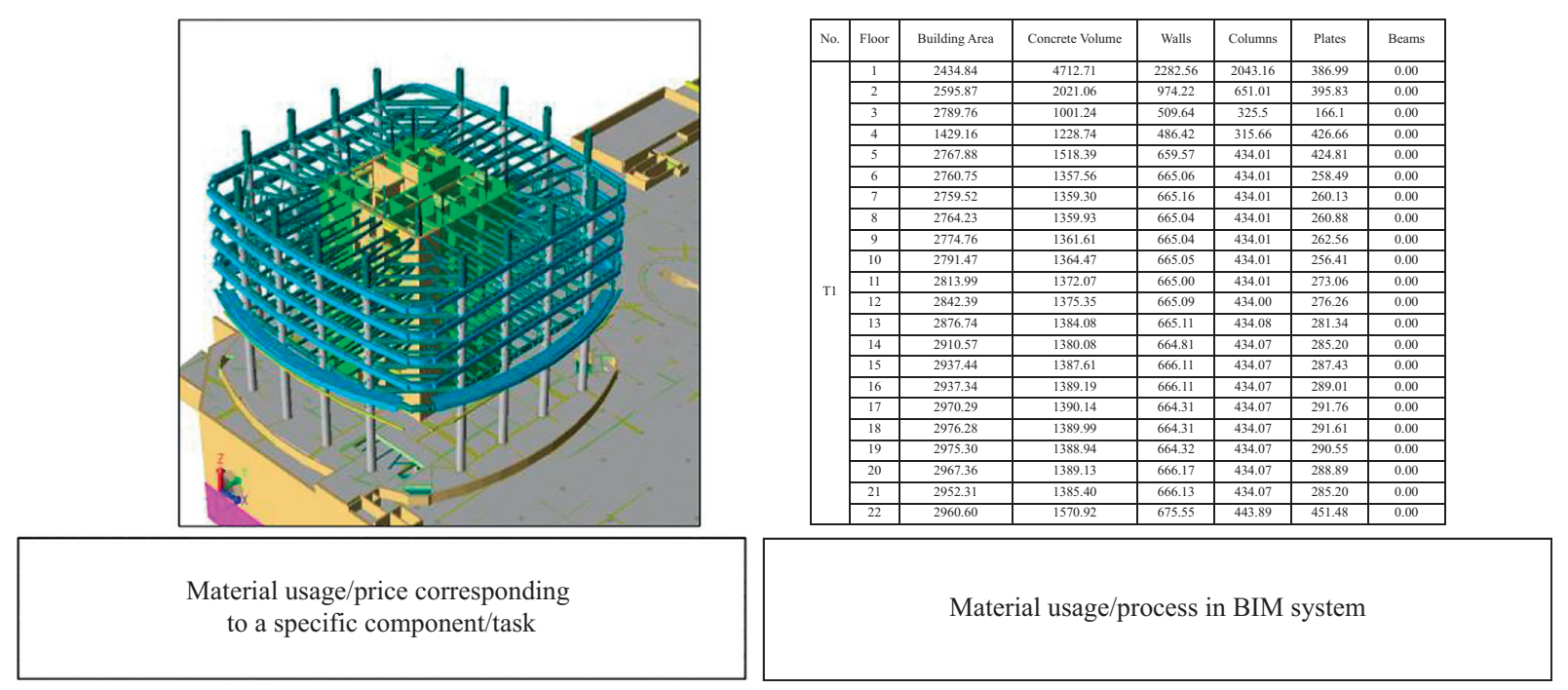

FIGURE 17: Enterprise quota management based on BIM.
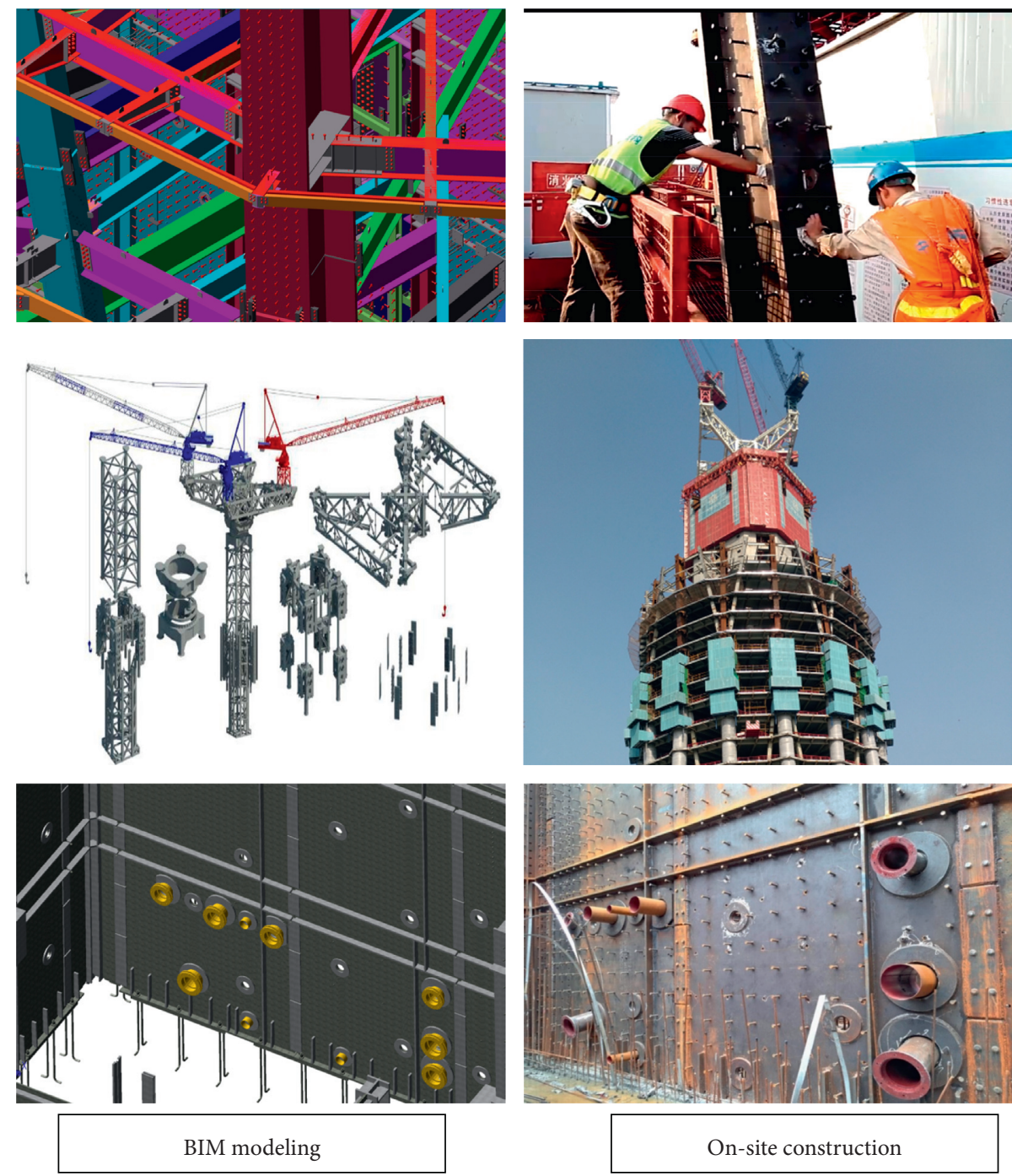

Figure 18: BIMs and process management on site. 
the actual progress (through cell phones, PCs, a monitoring control room, etc.) were compared and visually monitored to control the project schedule. For the consideration of enhancing construction speed and quality, a progress management model was also implemented. Some special working processes were developed in the BIM process database, including the movable scaffolding system for construction, temporary elevations in the core-cylinder, tower cranes with different sizes and working radii, and steel framework between the flat-type building and the tall tower. During the construction process, cost control was realized through the enterprise quota management model based on BIM. After a comprehensive survey on labor usage, price of raw materials, and manufacture in major construction enterprises in China, a dynamic supply-price-duration quota database was built in the BIM. Based on the owners' final project report, the application of the proposed 7D BIM helped owners save around $19.8 \%$ of fees in construction management, $35 \%$ in engineering design changes, and $15.8 \%$ in bidding process. The total duration of this project was also shortened by around 7 months (10\%), with good performance being achieved in construction quality, cost control, and quality control. After construction, the operation and maintenance could be conducted based on the data of the design and construction being integrated into a BIM operation system to improve the efficiency of management.

\section{Discussion}

This study proposed a 7D BIM to serve as a comprehensive BIM platform for the construction and operation of a complex project launched in China. The 7D BIM is composed of a 3D BIM, a 1D schedule management model, and a 3D project management model (bidding management model, enterprise quota management model, and process management model). As discussed in the Literature Review, academics and practitioners have come to a consensus that the 3D BIMs were visualized, $4 \mathrm{D}$ related to time, and $5 \mathrm{D}$ extended to cost $[21,22,30]$, while the $6 \mathrm{D}$ and the $7 \mathrm{D}$ BIMs lacked agreement [34-36]. The 4D BIM developed in this study, which contains the 3D BIM and a 1D schedule management model, was consistent with previous studies. However, unlike the stepwise extending of the model to 7D in other studies $[24,35,41]$, this study developed a $3 \mathrm{D}$ project management model to fulfil a bunch of functions including bidding management, enterprise quota management, and process management. The advantages of the extended 7D model in this study are as follows: Firstly, a bidding management model was developed to facilitate the bidding process through a visualized bidding function. Secondly, the emphasis of quota management in the 7D BIM enabled multiphase and life cycle cost control at the enterprise level, rather than only focusing on project construction cost in the traditional 5D BIM [30]. In the enterprise quota management model, the cost of design, construction, operation, maintenance, and even enterprise management could all be monitored. Lastly, the integration of the process management model with other models in the 7D BIM platform enhanced the cost and schedule management, which were vital in complex and tall building construction.

The success of this project validated the management structure which puts the BIM team and the BIM manager in the center of construction and operation process (shown in Figure 1). A professional BIM team was in charge of the overall management of the 7D BIM to solve the encountered difficulties, including modification/refinement of design, supervision, bidding, clash detection, schedule control, cost control, construction process control, maintenance, and operation. In addition, the owner of this project fully supported the BIM manager and fulfilled the needs of the BIM team. These findings implied that, apart from developing $\mathrm{nD}$ BIMs, the implementation and management of the model were equally important in achieving project success. The manner and importance of leadership of the BIM management team and trust of the owner in BIM application raised by Liu et al. [45] were demonstrated by this study. The experience of the project in this study also helped solve the problem stated by Herr and Fischer [15] that "most Chinese design and construction processes are highly linearized and characterized by a separation of professions with each AEC profession constructing proprietary BIMs."

Internet of Things made great contributions to communication facilitating and process monitoring in this study. The Internet of Things (IoT) was embedded in the 7D BIM, including construction process modeling, project supervision, modeling comparison, process realization, construction process control, quality control, and on-site management. Project stakeholders including owners, BIM team, construction companies, contractors, supervision teams, and suppliers could view and check the project progress, figure out problems, tap potentials, meet demands, and model/refine the project plans, through a unified BIM platform. Advanced communication technology played an important role in the project information exchange, which helped engineers/managers/owners to view and supervise the construction process through pads, cell phones, BIM system, and enterprise-level data centers. Thus, this study proved that the integration of BIM and IoT facilitated the collection and exchange of information for project construction, operation, and maintenance, which should become the future direction of BIM usage [33].

There are also some limitations for the application of this comprehensive BIM. Firstly, concerning the vital and central role which the BIM team undertakes, the price the owner paid for their expertise is not cheap compared with ordinary projects. Secondly, the integration of IoT into the BIM requires investment and installation of many advanced sensors/monitors/cameras, communication devices, and related products, which also needs extra cost. The owners or BIM teams who have no access to IoT or are unwilling to pay the price of IoT may not be able to monitor their projects through this approach. Thirdly, the working process or construction procedure is made based on the current Chinese construction market, where labor, managers, and BIM team members work for three shifts during weekdays. This may be not suitable for some countries or regions. 
Lastly, the construction process, biding management, cost control, and on-site supervision also have been regulated by both owners and local authorities with legislation [46, 47], which may be different in other regions.

\section{Conclusion}

This paper presents a 7D BIM and its application in a complex project launched in China. The proposed BIM system is composed of a traditional 3D BIM, a 1D schedule management model, and a 3D project management model. The management structure of this project is modified to assign the BIM manager and BIM team at the top level. For the consideration of modern BIM management and efficiency enhancement, the Internet of Things is adopted to provide clear $3 \mathrm{D}$ vision for modeling the construction process, on-site management, and interaction between field work and related management teams/contractors through the 7D BIM platform. In addition, a project and enterpriselevel data center is established for the life cycle project management. The application of the 7D BIM has been demonstrated with good performance being achieved in the case study, e.g., cost saving, efficiency and quality improvement, and construction period shortening. The integration of a 3D project management model with a traditional 3D BIM and a 1D schedule management model enables multiple functions of project management, including clash detection, structure design, modification, equipment installation, process simulation, facilities management, project operation, and life cycle maintenance.

This paper contributes to the body of knowledge in the following ways. First, this study proposed an innovation way of 7D BIM development by integrating a 3D project management model into the traditional 4D BIM. A bunch of new functions were achieved by the $3 \mathrm{D}$ project management models, including a visualized bidding management model, an enterprise level of quota management model, and a life cycle process management model. Second, the core position of the BIM team in the project management team structure in this study was the key to the success of the 7D BIM implementation. This finding provided significant implications for future BIM management. Previous studies were more focusing on the technical aspects of BIM application, such as the software, format, dimensions, and functions of the model. The soft aspects of BIM implementation, including BIM management, BIM team authorities, and owners' trust and support, should be highlighted in future studies. Last but not least, this study demonstrated that the integration of IoT into the 7D BIM significantly facilitated information collection and communication in the project. Advanced technologies such as $4 \mathrm{G}$ and $5 \mathrm{G}$ telecommunications in data collection, information storage and exchange, and real-time communication have greatly changed the way of construction management. Although the installation of IoT as well as the 7D BIM adoption and implementation required extra costs, their contributions to the overall project cost savings and time shortening should be highlighted and validated in future studies.

\section{Data Availability}

Some or all data, models, or codes generated or used during the study are available from the corresponding author upon request.

\section{Conflicts of Interest}

The authors declare no conflicts of interest.

\section{Acknowledgments}

This work was supported by the National Social Science Fund of China (Youth Project) (no. 17CSH028).

\section{References}

[1] J. Ma, M. Qian, C. Yu, and X. Yu, "Compressibility evaluation of reconstituted clays with various initial water contents," Journal of Performance of Constructed Facilities, vol. 32, Article ID 4018077, 2018.

[2] C. Yu, R. Liao, C. Zhu, X. Cai, and J. Ma, "Test on the stabilization of oil-contaminated wenzhou clay by cement," Advances in Civil Engineering, vol. 2018, Article ID 9675479, 9 pages, 2018.

[3] X. Yu, Q. Zhan, C. Qian, J. Ma, and Y. Liang, “The optimal formulation of bio-carbonate and bio-magnesium phosphate cement to reduce ammonia emission," Journal of Cleaner Production, vol. 240, Article ID 118156, 2019.

[4] Y.-C. Lin, S. Jung, and Y.-C. Su, "Construction databasesupported and BIM-based interface communication and management: a pilot project," Advances in Civil Engineering, vol. 2019, Article ID 8367131, 12 pages, 2019.

[5] J. Li, K. Afsari, N. Li, J. Peng, Z. Wu, and H. Cui, “A review for presenting building information modeling education and research in China," Journal of Cleaner Production, vol. 259, Article ID 120885, 2020.

[6] A. Ghaffarianhoseini, J. Tookey, A. Ghaffarianhoseini et al., "Building Information Modelling (BIM) uptake: clear benefits, understanding its implementation, risks and challenges," Renewable and Sustainable Energy Reviews, vol. 75, pp. 1046-1053, 2017.

[7] S. Azhar, M. Khalfan, and T. Maqsood, "Building information modelling (BIM): now and beyond," Australasian Journal of Construction Economics and Building, vol. 12, pp. 15-28, 2012.

[8] R. Masood, M. K. N. Kharal, and A. R. Nasir, "Is BIM adoption advantageous for construction industry of Pakistan?” Procedia Engineering, vol. 77, pp. 229-238, 2014.

[9] J. Li, N. Li, J. Peng, H. Cui, and Z. Wu, "A review of currently applied building information modeling tools of constructions in China," Journal of Cleaner Production, vol. 201, pp. 358-368, 2018.

[10] H. Aladag, G. Demirdögen, and Z. Isık, "Building information modeling (BIM) use in Turkish construction industry," Procedia Engineering, vol. 161, pp. 174-179, 2016.

[11] D. Cao, G. Wang, H. Li, M. Skitmore, T. Huang, and W. Zhang, "Practices and effectiveness of building information modelling in construction projects in China," Automation in Construction, vol. 49, pp. 113-122, 2015.

[12] D. Bryde, M. Broquetas, and J. M. Volm, "The project benefits of building information modelling (BIM)," International Journal of Project Management, vol. 31, no. 7, pp. 971-980, 2013.

[13] D. W. M. Chan, T. O. Olawumi, and A. M. L. Ho, "Perceived benefits of and barriers to Building Information Modelling (BIM) implementation in construction: the case of Hong 
Kong," Journal of Building Engineering, vol. 25, Article ID 100764, 2019.

[14] D. Walasek and A. Barszcz, "Analysis of the adoption rate of building information modeling [BIM] and its return on investment [ROI]," Procedia Engineering, vol. 172, pp. 1227-1234, 2017.

[15] C. M. Herr and T. Fischer, "BIM adoption across the Chinese AEC industries: an extended BIM adoption model," Journal of Computational Design and Engineering, vol. 6, no. 2, pp. 173-178, 2019.

[16] S. A. Jones and H. M. Bernstein, The Business Value of BIM in North America Multi Year Trend Analysis and User Ratings (200-2012, McGraw-Hill Construction, New York, NY, USA, 2012.

[17] NBS, National BIM Report, NBS National BIM Library, Newcastle upon Tyne, UK, 2013.

[18] H. Lindblad, "Study of the implementation process of BIM in construction projects: analysis of the barriers limiting BIM adoption in the AEC-industry," Master thesis, KTH Stockholm, Stockholm, Sweden, 2013.

[19] MOHURD, "Guideline on the application of building information modelling guiding opinions on promoting building information models," 2015, http://www.mohurd.gov.cn/wjfb/ 201507/t20150701_222741.html.

[20] L. Ding, Y. Zhou, and B. Akinci, "Building Information Modeling (BIM) application framework: the process of expanding from 3D to computable nD," Automation in Construction, vol. 46, pp. 82-93, 2014.

[21] I. Czmoch and A. Pękala, "Traditional design versus BIM based design," Procedia Engineering, vol. 91, pp. 210-215, 2014.

[22] R. Charef, H. Alaka, and S. Emmitt, "Beyond the third dimension of BIM: a systematic review of literature and assessment of professional views," Journal of Building Engineering, vol. 19, pp. 242-257, 2018.

[23] J. P. Zhang and Z. Z. Hu, "BIM-and 4D-based integrated solution of analysis and management for conflicts and structural safety problems during construction: 1 . Principles and methodologies," Automation in Construction, vol. 20, no. 2, pp. 155-166, 2011.

[24] C. Panteli, A. Kylili, and P. A. Fokaides, "Building information modelling applications in smart buildings: from design to commissioning and beyond a critical review," Journal of Cleaner Production, vol. 265, Article ID 121766, 2020.

[25] R. N. F. Sloot, A. Heutink, and J. T. Voordijk, "Assessing usefulness of 4D BIM tools in risk mitigation strategies," Automation in Construction, vol. 106, Article ID 102881, 2019.

[26] S. Su, Q. Wang, L. Han, J. Hong, and Z. Liu, "BIM-DLCA: an integrated dynamic environmental impact assessment model for buildings," Building and Environment, vol. 183, Article ID 107218, 2020 .

[27] J. Jupp, “4D BIM for environmental planning and management," Procedia Engineering, vol. 180, pp. 190-201, 2017.

[28] B. C. Guerra, F. Leite, and K. M. Faust, "4D-BIM to enhance construction waste reuse and recycle planning: case studies on concrete and drywall waste streams," Waste Management, vol. 116, pp. 79-90, 2020.

[29] R. Bortolini, C. T. Formoso, and D. D. Viana, "Site logistics planning and control for engineer-to-order prefabricated building systems using BIM 4D modeling," Automation in Construction, vol. 98, pp. 248-264, 2019.

[30] P. Smith, "BIM \& the 5D project cost manager," ProcediaSocial and Behavioral Sciences, vol. 119, pp. 475-484, 2014.

[31] J. Xu, "Research on application of BIM 5D technology in central grand project," Procedia Engineering, vol. 174, pp. 600-610, 2017.
[32] J. J. McArthur, "A building information management (BIM) framework and supporting case study for existing building operations, maintenance and sustainability," Procedia Engineering, vol. 118, pp. 1104-1111, 2015.

[33] S. Tang, D. R. Shelden, C. M. Eastman, P. Pishdad-Bozorgi, and X. Gao, "A review of building information modeling (BIM) and the internet of things (IoT) devices integration: present status and future trends," Automation in Construction, vol. 101, pp. 127-139, 2019.

[34] I. Motawa and A. Almarshad, "A knowledge-based BIM system for building maintenance," Automation in Construction, vol. 29, pp. 173-182, 2013.

[35] B. Grzyl, E. Miszewska-Urbańska, and M. Apollo, "Building information modelling as an opportunity and risk for stakeholders involved in construction investment process," Procedia Engineering, vol. 196, pp. 1026-1033, 2017.

[36] A. Koutamanis, "Dimensionality in BIM: why BIM cannot have more than four dimensions?" Automation in Construction, vol. 114, Article ID 103153, 2020.

[37] E. M. Wetzel and W. Y. Thabet, "The use of a BIM-based framework to support safe facility management processes," Automation in Construction, vol. 60, pp. 12-24, 2015.

[38] Y. Zhai, K. Chen, J. X. Zhou et al., "An Internet of Thingsenabled BIM platform for modular integrated construction: a case study in Hong Kong," Advanced Engineering Informatics, vol. 42, Article ID 100997, 2019.

[39] S. Maltese, L. C. Tagliabue, F. R. Cecconi, D. Pasini, M. Manfren, and A. L. C. Ciribini, "Sustainability assessment through green BIM for environmental, social and economic efficiency," Procedia Engineering, vol. 180, pp. 520-530, 2017.

[40] A. Motamedi, A. Hammad, and Y. Asen, "Knowledge-assisted BIM-based visual analytics for failure root cause detection in facilities management," Automation in Construction, vol. 43, pp. 73-83, 2014.

[41] A. K. Nicał and W. Wodyński, "Enhancing facility management through BIM 6D," Procedia Engineering, vol. 164, pp. 299-306, 2016.

[42] K. Chen, W. Lu, Y. Peng, S. Rowlinson, and G. Q. Huang, "Bridging BIM and building: from a literature review to an integrated conceptual framework," International Journal of Project Management, vol. 33, no. 6, pp. 1405-1416, 2015.

[43] A. Candelario-Garrido, J. García-Sanz-Calcedo, and A. M. Reyes Rodríguez, "A quantitative analysis on the feasibility of 4D Planning Graphic Systems versus conventional systems in building projects," Sustainable Cities and Society, vol. 35, pp. 378-384, 2017.

[44] M. Sheikhkhoshkar, F. Pour Rahimian, M. H. Kaveh, M. R. Hosseini, and D. J. Edwards, "Automated planning of concrete joint layouts with 4D-BIM," Automation in Construction, vol. 107, Article ID 102943, 2019.

[45] Y. Liu, S. Van Nederveen, and M. Hertogh, "Understanding effects of BIM on collaborative design and construction: an empirical study in China," International Journal of Project Management, vol. 35, no. 4, pp. 686-698, 2017.

[46] M. Lei, D. Liu, J. Liu et al., "Modified chloride diffusion model for concrete under the coupling effect of mechanical load and chloride salt environment," AIP Advances, vol. 8, Article ID 35029, 2018.

[47] L. Huang, J. Ma, M. Lei, L. Liu, Y. Lin, and Z. Zhang, "Soilwater inrush induced shield tunnel lining damage and its stabilization: a case study," Tunnelling and Underground Space Technology, vol. 97, Article ID 103290, 2020. 